\title{
Scrutinizing Factors Impeding Research-Farmer Relationship in the Context of the Agriculture Innovation System
}

\author{
Debella Deressa Bayissa \\ Department of Rural Development and Agricultural Extension, Institute of Cooperatives and Development Studies, Ambo \\ University, Ambo, Ethiopia
}

\begin{abstract}
The objective of this research was to scrutinize factors that impeded research-farmer relationship in the context of agricultural innovation system from researchers' perspective in Ethiopia. The research design used for this study was qualitative research approach. Respondents were interviewed using a snowball sampling technique. Data were collected primarily using in-depth interview, documents and analysed descriptively using the principle of grounded theory. The study revealed that research-farmer relationship was affected by resource scarcity and inefficient use; feebleness of the extension system; narrow vision among researchers and farmers; inadequate preparedness to share knowledge; weak coordination among the various actors; poor attention for research; inefficient use of research results; lack of attractive rewarding system and farmers' attitude for research and researchers. The conclusion is that the number of researchers to conduct demand-driven research was insufficient. Moreover, the scarce resources were inefficiently used by the various stakeholders conducting research that is less relevant to farmers need. The extension system of the country did not encourage researchers to work with farmers. The recommendations from the research is that the government of the country can take actions that can improve the relationship of researchers with farmers by employing knowledgeable, skilful, dedicated, concerned and committed people in knowledge institutes; allocating sufficient budget for research and changing the linear extension system to agricultural innovation system.
\end{abstract}

Key Words: Agricultural research; farmer; relationship; innovation system; Ethiopia

\section{Introduction}

Ethiopia is one the most populous countries in Africa. Its economy depends on agriculture (Bayissa and Paul, 2015; Spielman D. and K. Davis, 2011). The development of the country critically relays on the development of agriculture. Ethiopia has different agro-ecological zones that are highly conducive for cultivation of different types of crops and rearing of animals (Wigboldus et al., 2011). She has dedicated on developing agriculture to bring food security for resource poor farmers. The government has formulated different strategies to boost agricultural production and productivity. Moreover, the government has put pronounced exertions to escalate agricultural production and productivity. However, the anticipated outputs, augmentation in agricultural production and productivity, have not been attained yet. The root causes of low agricultural production and productivity are lack of appropriate technologies for farmers; weak innovation in agriculture due to weak relationship between researchers and farmers; the use of traditional farming systems; poor access to market; low adoption of agricultural innovations by farmers; weak linkage of researchers with farmers and lack of incentives for the stakeholders engaged in agricultural works (Spielman. \& Davis, 2011; Pender J. and B. Ge- bremedhin, 2008; Abate et al., 2011; IFAD, 2009). Weak relationship between farmers and researchers is one of the factors for limited innovation in agriculture (Wigboldus et al., 2011; Belay, 2002). This problem resulted in fragmentation of knowledge system. The technologies, skills or knowledge produced by farmers or researchers are not well transferred or exchanged to the various actors that are involved in agricultural innovation to bring food security (Belay, 2008). Therefore, the objective of this research was to scrutinize factors that impeded research-farmer relationship in the context of agricultural innovation system in Ethiopia. Examining these disabling factors help public authorities and policy makers to pay utmost effort to solve these limiting factors in agricultural innovation system in the country.

Corresponding author: Debella Deressa Bayissa, Department of Rural Development and Agricultural Extension, Institute of Cooperatives and Development Studies, Ambo University, Ambo, Ethiopia. Email: dabalaataf@gmail.com

This article is distributed under the terms of the Creative Commons Attribution License, which permits unrestricted use and redistribution provided that the original author and source are credited. 


\section{Theoretical Framework}

Different evidences showed that various approaches have been applied to boost agricultural production and productivity. Innovation in agriculture has been started before 45 years in various forms (Klerkx et al., 2012). Training and Visit System, Induced Innovation, Agricultural Knowledge and Information Systems, Participatory Research and Participatory Technology Development, Transfer of Technology system and Agricultural Innovation Systems (AIS) are among the various innovations types in agriculture. AIS are one of the recent perspectives in a family of systems approach in agricultural development (Klerkx et al., 2012; Brooks S. and M. Loevinsohn, 2011). From theoretical point of view, AIS is defined as "a network of organizations, enterprises, and individuals focused on bringing new products, new processes, and new forms of organization into economic use, together with the institutions that affect the way different agents interact, share, access, exchange and use knowledge"' (Hall et al., 2006).

\section{The importance of research in innovation system}

The relationship of researchers with farmers is changing as the pipeline process is not effective. The traditional institutional notion to scientists has been seeing as a source of agricultural technologies and knowledge. This dominant approach separates farmers from researchers and hindered their relationship. As a result of this problem, agricultural innovation comes from various stakeholders including farmers and researchers to bring impact on conducting agricultural research that is relevant to the users of the technologies by engaging them in technology and knowledge production, diffusion and use. Effective and strong relationship of farmers and researchers has alleviated the problems of agricultural production in many countries like postharvest loss in Indian farmers. Effective relationship of farmers with researchers has brought solutions in agriculture as farmers are engaged in the innovation process of technology and knowledge development and utilization. From innovation systems approach, innovation comes from systems of stakeholders. Learning is the most crucial aspect of the system that comes from strong relationship of farmers with researchers engaged in knowledge creation, diffusion and utilization (Klerkx L. and C. Leeuwis, 2009; Hall et al., 2001; Andrew Hall et al., 2003). In most African countries, the relationship between research and farmer is weak. Researchers have weak interaction with farmers to exchange knowledge and to bring learning and innovation (Sumberg, 2005).

\section{The significance of strong research-farmer rela- tionship}

Effective and strong research-farmer relationship is highly critical for the development of knowledge that is demand-driven to farmers and created when both farmers and researchers interact on continuous bases (Sumberg, 2005). From AIS perspective, farmers are fundamentally important in building knowledge and adding it to the innovation process to bring national food security (Klerkx L. and C. Leeuwis, 2009).

\section{The value of farmers participation in agricul- tural research}

Hellin et al. (2008) defined participatory agricultural research "as a systematic dialogue between farmers and scientists to solve problems related to agriculture, and ultimately to increase the impact of agricultural research." Effective and strong relationship of research-farmer is highly important to conduct demand driven research to solve farmers' problems. According to Neef and Neubert (2011), farmers' participation in research is viewed as a multi-dimensional process. Research-farmer relationship is one of the scopes of farmers' participation in agricultural innovation. With the augmented attention on "sustainable agricultural development", where economic, social and ecological factors need to be well-adjusted, it has been acknowledged that a variety of actors like farmers, consumers, extension workers and researchers are pertinent in the research method in agricultural innovation to bring food security. As a consequence, today "participation in agricultural research is defined as the involvement of all individuals and groups who are directly and indirectly affected by the research activities and its outcomes (Neef et al., 2006).

Moreover, the question of the focuses of control and decision-making of the research practice has to be detached from the concern of pure stakeholder commitment in the research; it hints the embodiment of power relations between researchers and farmers (Ashby, 2003). Even in conditions where proper involvement of farmers is vital in agricultural research, researchers do still device the research process and are at the heart of decisionmaking. Furthermore, it is known that farmers and researchers have various comparative profits in generating knowledge. For example, Maori farmers from New Zealand, in a research project, were insisting that their own traditional knowledge - obtained through long term experience and passed down through elders would be merged with researchers' technical knowledge rather than being by it (Hoffmann et al., 2007; Neef,2005; Van Asten et al., 2009). 


\section{Research Methodology}

Contemporary researchers in social sciences have started to put more attention on the use of qualitative research methods, i.e., methods by means of which one can study non-quantitative characteristics of empirical phenomena. Data were generated primarily from knowledge institutes (Wallaga University and Ambo Plant Protection Research Centre), Development agents and Farmers from Western Oromia through in-depth interviews. A total sample size of 79 respondents comprising 29 farmers, 27 researchers and 23 development agents were interviewed purposively based on snowball sampling technique. The researchers interviewed were working as lecturers at Wallaga University besides working as researchers in agricultural sector. They were people having many years of research experiences in various institutes working for the betterment of the society. Most of them were
PhD holders from various universities. The data were also collected from Ambo Plant Protection Research Centre. Researchers working at this institution have long years of research experiences. Most of them were senior researchers and worked at different research institutions at different positions. From the 27 researchers interviewed 19 were men and 8 were females. The research was conducted in Western Oromia, Ethiopia. Ambo Plant Protection Research Centre is located in Western Showa zone of Oromia region. Wallaga University is located in Eastern Wallaga zone of Oromia region. The research area has high population density that is mostly living in the rural areas. Farmers are using traditional way of farming and yet household food security is not achieved yet. Most of the farmers are illiterate and the use of new agricultural technologies is very low. Farmers do not have the knowledge and skills to use new agricultural technologies to improve their lives.

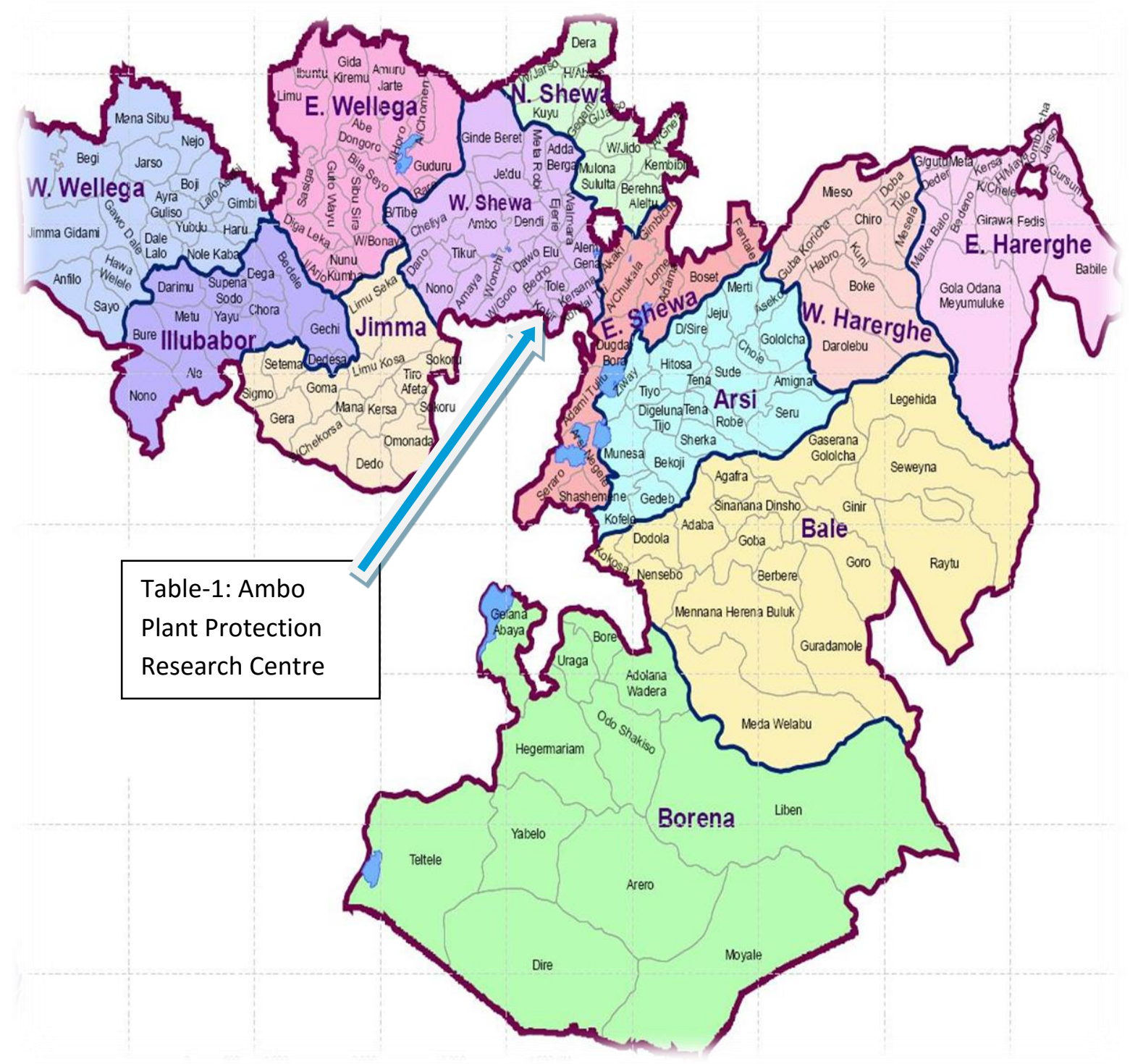

Figure 1. Map of Oromia regional state, Ethiopia 
A qualitative research design was used in this research. Triangulation between different data sources took place to ensure validity (Yin, 2003). Interviews were fully transcribed, translated and coded applying principles of grounded theory (Glaser, and Strauss, 1967) before it was descriptively analysed. Translation follows transcription of data before analysis. Facilitating a qualitative research interview is a hard work and difficult to write down responses while maintaining eye contact, providing encouragement and planning the prompt, probe or link to the next topic of interest, listening and other activities. Therefore, the interview was recorded on memory recorder. Key informants were mostly used as a means of gaining access to the interviewee. Also observation was taken place in the role of observer- as- participant (Angrosino M, 2007), in which the research relates to and was known to the subjects under study as a researcher. Observation was performed during annual prioritization meeting, research reviews, and field demonstrations. Existing documents were used as sources of data for this research since it can be efficient sources for qualitative questions.

In qualitative research the sample size for the interview depends on the aim of the research. Most qualitative research has the aim of purposive sampling which is explicitly selecting interviewees who it is intended will generate appropriate data. The overall aim of purposive as opposed to probability sampling is to contain information rich cases for in-depth study. To achieve this snowball sampling was used. The best methodological answer to sample size in qualitative research is a grounded theory approach. The grounded theory approach is a qualitative research method that uses a systematic set of analytical, interpretative, and coding procedures, to develop an inductively derived grounded theory about a phenomenon. Grounded theory emerged in reaction to the formerly common practice of considering research only as a means of testing hypotheses. That means that the research started with theory that was subsequently tested. Grounded theory was developed as a systematic approach to develop theory on the basis of empirical research. The theory is then the 'finding' of the research. Grounded theory approach advocates theoretical sampling or including interviewees (the incidents and events that interviewees and other sources do provide) in the sample on the bases of both an emerging hypothesis from on-going data analysis, an understanding of the field and a delicate attempt to test such hypotheses. The objective is to keep sampling and analysing data until nothing new is being generated. This point is called saturation and the techniques are called sampling to saturation. When sufficient data are gathered it reaches theoretical saturation. In qualitative research 'statistical sig- nificance' of relations between the empirical phenomena which are being described is not a major criterion (Glaser, and Strauss, 1967). A better criterion is what has been called sociological significance. This shows that the researchers' interest is to examine whether the descriptions of these conceived relationships are understandable, meaningful and convincing for the people involved and for the outside world (Elias and Scotson, 1976).

In general, a systematic approach to qualitative data analysis is the use of the grounded theory. The procedure in grounded theory lies in a cyclical process of data collecting, analysing it, developing a provisional coding scheme, using this to suggest further sampling, more analysis, checking out emerging theory and so on until a point of saturation is reached, when no new constructs are emerging. At this point rich, dense theoretical account is achieved (Judith Green and Nicki Thorogood, 2009).

\section{Results}

The research findings showed that research-farmer relationship was affected by a number of factors. From researchers' perspective these relationship limiting factors are listed and discussed as follows.

\section{Resource scarcity and its inefficient use}

The research findings showed that the number of researchers to conduct demand-driven research in the country was insufficient. As the county is one of the developing nations in the world, there was limitation in terms of educated manpower especially in research institutions. Moreover, there was high brain-drainage of the educated manpower. Most of the educated people left the country for the search of better life, payment and working environment. Some of the educated people migrated to the western world because of political reasons. The research also indicated that there was limitation of resources for conducting demand-driven research. These include limitation of vehicles, laboratory, budgets and better social services. Researchers told that there was great limitation of cars to use for research and this limited working with farmers. Government politicians were using recent model cars that were bought in millions of birr (Ethiopian currency) whereas researchers did not have the basic necessary cars that could be used to work with farmers engaging them in agricultural research to bring innovation to alleviate poverty. Even though there was resource limitation, the available resources were not efficiently used to bring development as soon as possible to make resources poor farmers the beneficiaries of agricultural technologies to change their lives. Besides the limitation of re- 
searchers, most of the farmers were uneducated. These factors hindered effective research-farmer relationship to bring innovation in agriculture.

\section{Feebleness of the extension system}

The research result showed that the extension system of the country was one of the factors that affected effective research-farmer relationship. Researchers were mostly engaged in technology development. Farmers were technology implementers without the necessary knowledge and skills of the technology developed by researchers. Development workers were in between researchers and farmers for the dissemination of the technologies. Researchers had little chance of engaging farmers in agricultural research as the extension system separated researchers from farmers through extension. Since there was little interaction of researchers with farmers in agricultural research, there was little room to share knowledge and experience. As a result, learning, the main focus of innovation system, was greatly affected. This lack of good research-farmer relationship affected innovation in agriculture and this hindered national food security.

\section{Inadequate vision among researchers and farmers}

The research result revealed that there was limitation of vision among the stakeholders in the country. This was the commonly shared idea among researchers who shared their ideas during the interview. This lack of common vision among the actors working in agriculture limited the interaction of researchers with farmers and hindered innovation in agriculture to bring food security for the resource poor farmers. Mostly researchers conducted research in the areas of their interest and experiences that had little relevance to the need of farmers. Even among researchers, there was limited vision as educated people working for the development of the country. Researchers working in universities perceived research as the work and obligation of researchers at research institutes. Educated people were not as such concerned for the poor and marginalized farmers. This emanated from lack of concern and dedication for the majority of the people living in the rural areas. Even educated people who came from the rural areas were not as such dedicated for the welfare of the society.

\section{Limited preparedness to share knowledge}

The study indicated that readiness and willingness to learn from the various stakeholders engaged in agricultural development was one of the factors that hindered effective research-farmer relationship. The problem was serious among researchers and farmers. Researchers were not ready and willing to learn from farmers. Researchers looked at farmers as uneducated and their knowledge was not important in the research process. Even researchers were not as such happy to share their knowledge and experiences. Forum for knowledge and experience sharing among researchers was inadequate to bring innovation in agriculture. Farmers were not getting sufficient knowledge from researchers about agricultural technologies. Researchers were not helping farmers to help themselves. Developing agricultural technology alone did not bring change in the lives of farmers. Researchers were not developing the capacity of farmers to enable them to help themselves.

\section{Lack of attractive rewarding system}

The study showed that the incentive mechanism to motivate researchers was weak. This discouraged researchers that had showed better performance in engaging farmers in agricultural research for knowledge sharing to bring innovation in agriculture. The rewarding system to differentiate researchers who had conducted demand-driven research from researchers that conducted research for their own publication was not encouraging. One of the researchers who were my respondents in the study areas told his observation about the rewarding system in the country as follows: "The rewarding system in the country is weak. The system does not differentiate researchers who have devoted their time and energy on research that can solve farmers' problems from those researchers who are working only to get salary. To bring change in the lives of farmers the government should establish a good rewarding system which can encourage researchers who are conducting demand driven research and discourage and divorce researchers who are not conducting demand driven research to solve farmers' problems. If there is a good rewarding system, differences among researchers are created and demand driven research that is relevant to farmers need is conducted. It also creates competition among researchers and helps to develop competent and strong researchers."

The above quote was the commonly shared view among researchers in the study areas. The government was not rewarding researchers that had showed better performance by conducting research engaging farmers in the research process to solve the problems of resources poor farmers. Researchers who had good relationship with farmers were not encouraged to involve farmers in agricultural research to bring innovation in agriculture to feed the growing population. Scientists who had worked for the society and brought impact on the lives of resource poor farmers 
were not encouraged in the form of rewards, incentives, and recognitions.

\section{Farmers' attitude for research and researchers}

The research revealed that farmers' perception for research and researchers was one of the factors hindering effective research-farmer relationship. Farmers' perceived research as a complex and difficult activity that has to be done by people who were educated. Moreover, farmers perceived researchers as a boss and difficult for them to work with them. Moreover, farmers undermined themselves in the research process due to their position associated to their academic status. Furthermore, farmers had thought that their knowledge did not make them partners of researchers. Farmers looked researchers as outsiders. Farmers did not have the trust that researchers produce agricultural technologies that solve their problems by conducting research. This greatly affected the relationship of farmers with researchers in a negative ways.

\section{Weak coordination}

The research conducted shown that the coordination among the stakeholders engaged in agricultural development was weak. This weak coordination among the actors working for the development of the country resulted in duplication and wastage of resources. The country had limited resources to bring development to make the resource poor farmers beneficiaries of the development. However, due to weak coordination among the various groups working, these scarce resources were not efficiently and effectively used to bring development for the needy ones. This problem emanated from lack of strong institution that coordinate the efforts of the stakeholders that were involved in the development of the country. Even the coordination among knowledge institutes was weak. Researchers in universities perceived research as the work of researchers that were working in research institutions. Moreover, the forum for sharing experience and knowledge was limited. Researchers did not have adequate forum for experience and knowledge sharing due to lack of strong coordinating body. This greatly affected the relationship of researchers with farmers.

\section{Little attention for research}

The study conducted indicated that the attention given to research from the government was not encouraging. The government was not satisfied with the work of researchers that they were contributing in the development of the country. Most of the research results were not problem solving to alleviate poverty. Moreover, researchers were not conducting research at peripheries engaging the poor and marginalized farmers. Furthermore, the research was not demanddriven. As a result, the attention from the government for research was weak. The budget for the purchase of the necessary materials to conduct research was not sufficient. This lack of attention from the government for research hindered effective relationship of researchers with farmers to engage them in the research process to bring innovation in agriculture.

\section{Inefficient use of research results}

The research findings revealed that inefficient use of research results was one of the factors that limited the interaction of researchers with farmers. The research results were not efficiently used by policy makers. Most of the research results were shelved and little used by the government to bring development. The government had little trust in the research results development locally by local researchers. The government mostly used foreign research results and recommendations for the formulation of development policies and strategies. This demotivated researchers to work with farmers. Moreover, researchers were discouraged to conduct demand-driven research by engaging farmers in the research process to benefit resource poor farmers from the research works.

\section{Discussion}

The research result revealed that a number of factors affected research-farmer relationship in agricultural research from researchers' perspectives. These factors limited the engagement of farmers in research process to bring innovation in agriculture. Many empirical evidences (Bayissa and Paul, 2015; Wigboldus et al., 2011; Abate et al., 2011; Belay K, 2008) confirm that resource limitation is one of the factors that critically affect research-farmer relationship to bring innovation in agriculture. Moreover, inefficient uses of the available resource fundamentally affect the engagement of all stakeholders in agricultural research to contribute their share in the development of knowledge and technology for the improvement of resource poor farmers. Furthermore, researcherfarmer ratio crucially limits the relationship of researchers with farmers to engage them in agricultural research to bring national food security. The findings of this research show similar cases with the works of (Bayissa and Paul, 2015; Spielman D. and K. Davis, 2011; Belay K, 2002) in that the linear extension system separates researchers from farmers through extension workers. This pipeline model reduces the 
interaction of researchers with farmers to bring innovation in agriculture. Innovation occurs from mutual interaction of the various stakeholders that are engaged in the development of agriculture. Since extension workers are technology disseminators, researchers have little opportunity to engage farmers in agricultural research starting from problem identification to the use of the technologies. Different research findings (Wigboldus et al., 2011; IFAD, 2009) affirm that lack of common vision for the development of the country hinders the interaction of researchers with farmers to bring innovation in agriculture. Working towards achieving a common goal for the development of the country is critically important to bring change in the lives of the society.

Many research evidences (Brooks S. and $\mathrm{M}$. Loevinsohn, 2011; Hall et al., 2006; Klerkx L. and C. Leeuwis, 2009) affirm that lack of willingness and readiness to share knowledge and experience among the various actors that are engaged in agricultural development is critical. Moreover, lack of forum for experience sharing can greatly hinder the interaction of farmers with researchers. According to the works of (Bayissa and Paul, 2015; Abate et al., 2011; Neef A. and D. Neubert, 2011; Ashby, 2003) rewarding system greatly affects the relationship of researches with farmers. Countries having good rewarding system for outstanding researchers for their extraordinary works can motivate these researchers to continue their work in sustainable manner besides inspiring other researchers to contribute their share in the development of the country. Poor rewarding systems highly discourage researchers to conduct demanddriven research and this fundamentally hinders effective relationship of researchers with farmers. This research shows similar findings with the works of (Neef et al., 2006; Hoffmann et al., 2007; Van Asten et al., 2009) that farmers' attitude for research and researchers fundamentally hinders their relationship with researchers. Farmers see research as a complex and challenging process that is beyond their capacity to work with researchers. Farmers perceive that research needs western knowledge. Moreover, farmers perceive that researchers are educated person and it is difficult for them to be partners in agricultural research. The findings of (Klerkx et al., 2012; Brooks S. and M. Loevinsohn, 2011; Hall et al., 2006; Klerkx L. and C. Leeuwis, 2009) indicate that lack of strong coordinating body among actors working for the development of the country fundamentally affects the relationship of researchers with farmers and other stakeholders. Lack of integration and coordination among all actors' results in duplication of efforts and wastage of resources that the country could ill to afford.
Agreeing to the findings of (Wigboldus et al., 2011; Pender J. and B. Gebremedhin, 2008; Belay K, 2002; Klerkx et al., 2012) attention for research from the government critically affect research-farmer relationship. Government attention for research is basically important to encourage researchers to work with farmers. Moreover, due attention from the government motivates researchers to conduct demanddriven research to solve farmers problems. Furthermore, strong attention from the government for research increase budget allocation for the purchase of the necessary materials to conduct research that is relevant to farmers need by engaging them in the research process to bring innovation in agriculture. Numerous research results (Bayissa and Paul, 2015; Wigboldus et al., 2011; Abate et al., 2011; Belay K, 2008) affirm that the use of indigenous research results by the government highly affect researchers' relationship with farmers and other stakeholders. Policy makers' use of local research results encourage researchers to conduct research that is relevant to the need of farmers by involving them in the research process starting from problem identification to empowering them to help themselves. Inadequate use of indigenous research results hinders researchers' dedication to actively work with farmers to bring innovation in agriculture that helps farmers to learn how to learn.

\section{Conclusions and Recommendations}

The research result revealed a number of issues that limited research-farmer relationship in the context of agricultural innovation from researchers' perspectives. From the research result, many conclusions can be made. The number of researchers to conduct demand-driven research was not sufficient. Moreover, the scarce resources were inefficiently used by the various stakeholders to conduct research that is relevant to farmers need. The extension system of the country did not encourage researchers to work with farmers. The extension system separated researchers from farmers and critically hindered innovation in agriculture to bring food security. Lack of common vision among the various actors in the development of agriculture was poor. There was little forum to share knowledge and skills among researchers and farmers to bring innovation. Integration and coordination among the different stakeholders especially farmers and researchers was poor. There was weak attention from the government for research and hindered agricultural development in the country. The use of research results for the formulation of development policies and strategies was not encouraging. The rewarding system for researchers was not encouraging to conduct demand-driven research. Farm- 
ers' attitude for research and researchers critically hindered effective interaction of researchers with farmers and hence affected innovation and delayed the development of the country.

From the research result, a number of recommendations can be given for the relevant stakeholders to use either for future research or development policy formulations. The government of the country can take actions that can improve the relationship of researchers with farmers by employing knowledgeable, skilful, dedicated, concerned, experienced and committed people in knowledge institutes; allocating sufficient budget for research; changing the linear extension system to agricultural innovation system; creating common vision among all stakeholders engaged in the development of the country; strengthening coordination and integration among the various actors; establishing forum for knowledge and experience sharing; giving due attention for research; efficient use of local research results for development policy and strategy formulation and rewarding researchers for their extraordinary achievements.

\section{References}

Abate T, Shiferaw B, Gebeyehu S, Amsalu B, Negash K and Assefa K. (2011). A systems and partnership approach to agricultural research for development: Lessons from Ethiopia. Outlook Agriculture, 40(3):213-220

Andrew Hall, V. Rasheed Sulaiman, Norman Clark and B. Yoganand. (2003). From measuring impact to learning institutional lessons: an innovation systems perspective on improving the management of international agricultural research. Agricultural Systems, 78 (2): 213-241.

Angrosino, M. (2007). Focus on Observation. Los Angeles, CA: Sage Publishers.

Ashby, J. (2003). Introduction: Uniting science and participation in the process of innovation-Research for development. In Managing natural resources for sustainable livelihoods: Uniting science and participation, ed. B. Pound, S. Snapp, C. McDougall, A.Braun, London: Earthscan, 1-19.

Belay K. (2002). "Constraints to extension work in Ethiopia: the insiders' view". South African Journal of Agricultural Extension, 31(1): 63-79

Belay K. (2008). "Linkage of higher education with agricultural research, extension and development in Ethiopia”. Higher Education Policy, 21(2): 275-299.

Brooks S. and M. Loevinsohn. (2011). "Shaping agricultural innovation systems responsive to food insecurity and climate change." Natural Resources Forum, 35(3):185- 200.

Elias, N. and J.L. Scotson. (1976). De gevestigden en buitenstaanders: Een studie van de spanningen en machtsverhoudingen tussen twee arbeidersbuurten. Uitgeverij Het Spectrum, Utrecht.
Debella Deressa Bayissa and J.Paul Mansingh.(2015). Investigating Farmers' Characteristics Affecting Their Linkage with Researchers in Agricultural Innovation in Ethiopia. Asian Journal of Agricultural Extension, Economics and Sociology, 7(4): 1-9.

Glaser, B. and A. Strauss. (1967). The discovery of Grounded Theory. Aldine, Chicago.

Hall, A., W. Janssen, E. Pehu and R. Rajalahti. (2006). Enhancing agricultural innovation: How to go beyond the strengthening of research systems. Washington: World Bank.

Hall A, Bockett G, Taylor S, Sivamohan MVK and Clark N. (2001). Why Research Partnerships Really Matter: Innovation Theory, Institutional Arrangements and Implications for Developing New Technology for the Poor. World Development, 29(5):783-797.

Hellin J., M.R. Bellon, L. Badstue, J. Dixon and R. La Rovere. (2008). Increasing the impacts of participatory research. Experimental Agriculture, 44 (1): 81-95.

Hoffmann, V., K. Probst and A. Christinck. (2007). Farmers as researchers: How can collaborative advantages are created in participatory research and technology development? Agriculture and Human Values, 24 (1): 355-368.

IFAD.(2009). Federal Democratic Republic of Ethiopia Country Programme Evaluation Report No. 2045-ET.

Judith Green and Nicki Thorogood. 2009. Qualitative methods for health research. Second Edition. Los Angeles, Sage publishers.

Klerkx L., B. van Mierlo and C. Leeuwis. (2012). Evolution of systems approaches to agricultural innovation: Concepts, analysis and interventions. In Elzen, B., M. Barbier, M. Cerf, and J. Grin (Eds.) Stimulating transitions towards sustainable farming systems. Dordrecht: Springer, 459-485.

Klerkx L. And C. Leeuwis. (2009). Operationalizing Demand-Driven Agricultural Research: Institutional Influences in a Public and Private System of Research Planning in the Netherlands." The Journal of Agricultural Education and Extension, 15(2): 161-175.

Neef A. and D. Neubert. (2011). Stakeholder participation in agricultural research projects: a conceptual framework for reflection and decision-making. Agriculture and Human Values, 28(2): 179-194.

Neef, A., F. Heidhues, K. Stahr, and P. Sruamsiri. (2006). Participatory and integrated research in mountainous regions of Thailand and Vietnam: Approaches and lessons learned. Journal of Mountain Science, 3(4): 305324.

Neef, A. (2005). Participatory approaches and local knowledge for sustainable land use - an introduction. In Participatory approaches for sustainable land use in Southeast Asia, ed. A. Neef, Bangkok: White Lotus, 3-32

Pender J. and B. Gebremedhin. (2008). "Determinants of Agricultural and Land Management Practices and Impacts on Crop Production and Household Income in the Highlands of Tigray, Ethiopia." Journal of African Economies, 17(3): 395-450.

Spielman D. and K. Davis. (2011). "Rural innovation systems and networks: findings from a study of Ethiopian 
smallholders." Agriculture and Human Values, 28(2): 195-212.

Sumberg J. (2005). Systems of innovation theory and the changing architecture of agricultural research in Africa. Food Policy, 30(1):21-41.

Van Asten, P.J.A., S. Kaaria, A.M. Fermont and R.J. Delve. (2009). Challenges and lessons when using farmer knowledge in agricultural research and development projects in Africa. Experimental Agriculture, 45: 1-14.
Wigboldus S., Jan van der Lee, Gareth Borman, Karen Buchanan and Wouter Leen Hijweege. (2011). Going for gold in innovation partnerships responsive to food insecurity - the role of knowledge institutes. Policy paper. Wageningen UR Centre for Development Innovation.

Yin, R.K. (2003). Case Study Research: Design and Methods. Thousand Oaks, CA: Sage Publications. 